\title{
INL FY2014 1st Quarterly Performance Analysis
}

\author{
Loran Kinghorn
}

July 2014

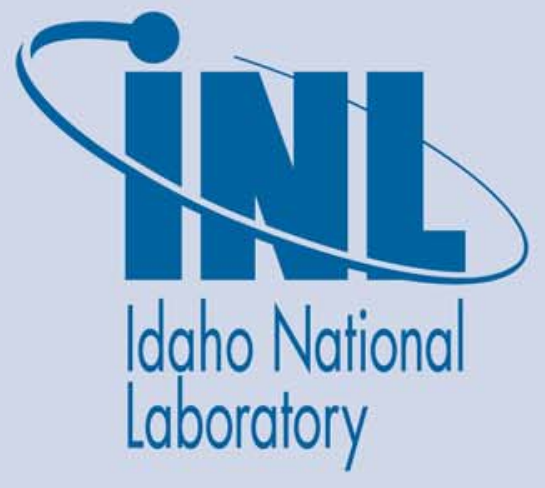

The INL is a U.S. Department of Energy National Laboratory operated by Battelle Energy Alliance 


\title{
INL FY2014 1st Quarterly Performance Analysis
}

\author{
Jim Kinghorn
}

July 2015

Idaho National Laboratory

Idaho Falls, Idaho 83415

http://www.inl.gov

\section{Prepared for the}

U.S. Department of Energy

Office of Nuclear Energy

Under DOE Idaho Operations Office

Contract DE-AC07-05ID14517 


\section{Idaho National Laboratory}

\section{Quarterly Performance Analysis}




\section{DISCLAIMER}

This information was prepared as an account of work sponsored by an agency of the U.S. Government. Neither the U.S. Government nor any agency thereof, nor any of their employees, makes any warranty, expressed or implied, or assumes any legal liability or responsibility for the accuracy, completeness, or usefulness, of any information, apparatus, product, or process disclosed, or represents that its use would not infringe privately owned rights. References herein to any specific commercial product, process, or service by trade name, trade mark, manufacturer, or otherwise, does not necessarily constitute or imply its endorsement, recommendation, or favoring by the U.S. Government or any agency thereof. The views and opinions of authors expressed herein do not necessarily state or reflect those of the U.S. Government or any agency thereof. 


\section{Contents}

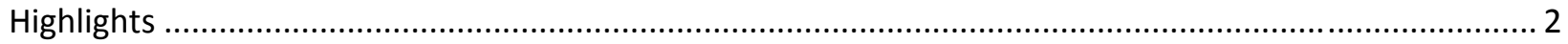

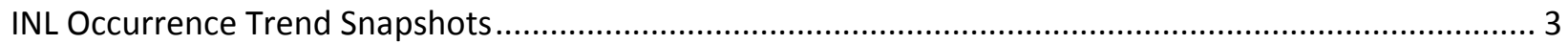

$1^{\text {st }}$ Qtr FY-14 KEY LESSONS LEARNED ISSUED BY INL ORGANIZATIONS ............................................ 4

$1^{\text {st }}$ Qtr FY-14 GROUP 1 - OPERATIONAL EMERGENCIES .............................................................. 7

$1^{\text {st }}$ Qtr FY-14 GROUP 2 - PERSONAL SAFETY AND HEALTH EVENTS …............................................. 8

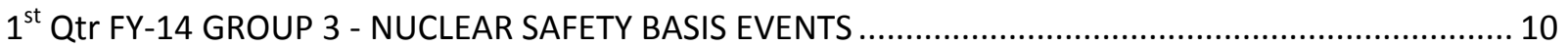

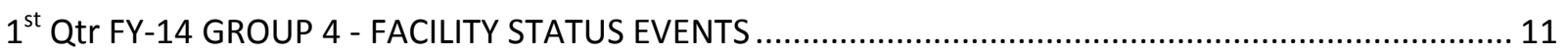

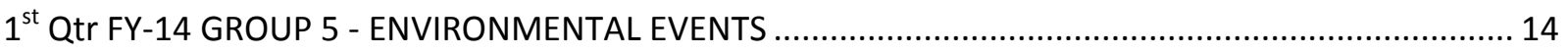

$1^{\text {st }}$ Qtr FY-14 GROUP 6 - CONTAMINATION/RADIATION CONTROL EVENTS......................................... 15

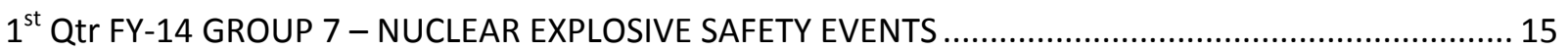

$1^{\text {st }}$ Qtr FY-14 GROUP 8 - PACKAGING AND TRANSPORTATION EVENTS ............................................ 15

$1^{\text {st }}$ Qtr FY-14 GROUP 9 - NONCOMPLIANCE NOTIFICATIONS EVENTS ............................................... 16

$1^{\text {st }}$ Qtr FY-14 GROUP 10 - MANAGEMENT CONCERNS AND ISSUES ............................................... 16

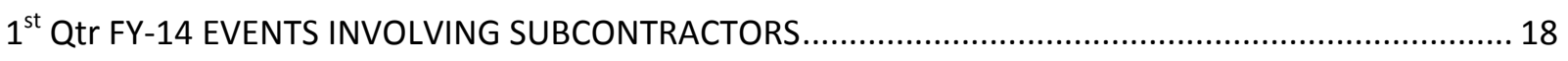

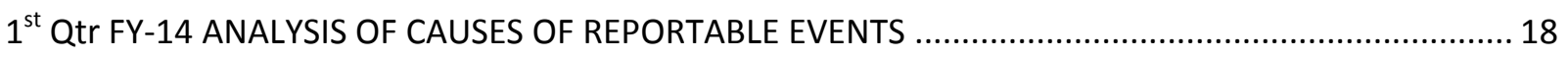

$1^{\text {st }}$ Qtr FY-14 ANALYSIS OF IOPAC TRENDING ANALYSIS ................................................................ 19 
INL/EXT-14-31237

FY-14 1 ${ }^{\text {st }}$ Quarter

This report is published quarterly by the Idaho National Laboratory (INL) Performance Assurance Organization.

The Department of

Energy Occurrence Reporting and Processing System (ORPS), as prescribed in DOE Order 232.2, "Occurrence Reporting and Processing of Operations

Information," requires a quarterly analysis of events, both reportable and not reportable, for the previous 12 months. This report is the analysis of 76 occurrence reports and over 15 other deficiency reports (including not reportable events) identified at INL from October 2013 through December 2013.

Battelle Energy

Alliance (BEA) operates the INL under contract

DE-AC07-051D14517

\section{Highlights...}

The average number of occurrences reported at the INL each quarter has remained consistent between 18 and 19. The rate of significant events (those reported as Operational Emergencies, Recurring Issues, and/or Significance Categories 1 or 2) trend continues to increase, however, the $1^{\text {st }}$ Qtr FY-14 has seen a decrease in events to a total of two.

The average number of days between significant occurrences has been decreasing.

This quarterly analysis reviews those events that were reportable through ORPS, events that did not meet ORPS reporting thresholds, some deficiencies tracked in ICAMS/LabWay, the causes of reportable events, and trending performed by the INL Operational

Performance Analysis Committee (IOPAC) group.

The report also provides a summary of the more significant Lessons Learned issued by INL.
Occurrence Reporting Rates as of FY14 Qtr 1

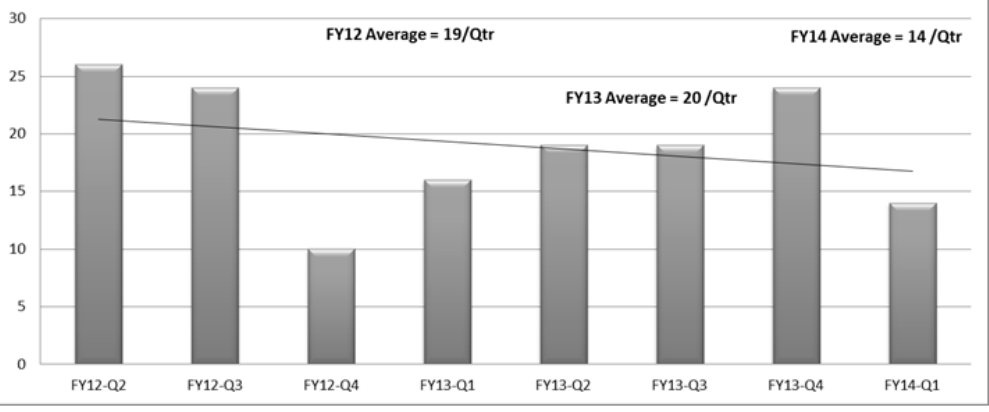

Significant Occurrences Reported (Category OE, R, 1, and 2)

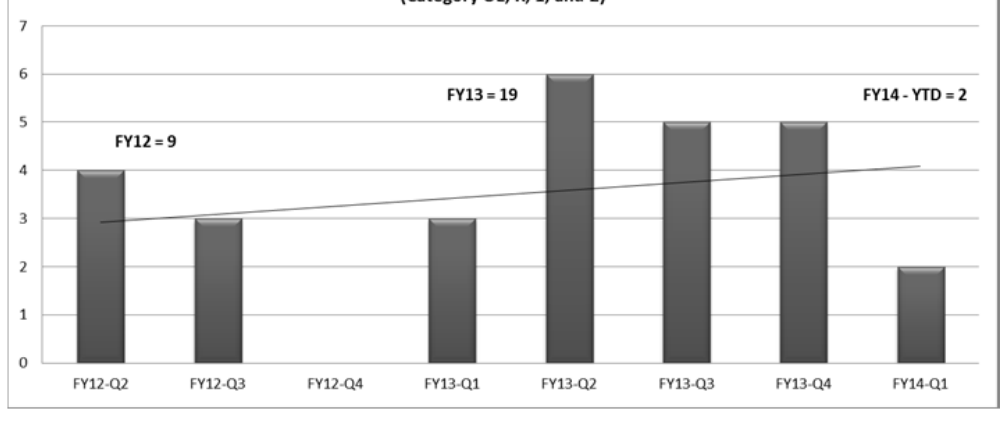

Average Days Between Significant Occurrences (Category OE, R, 1, and 2)

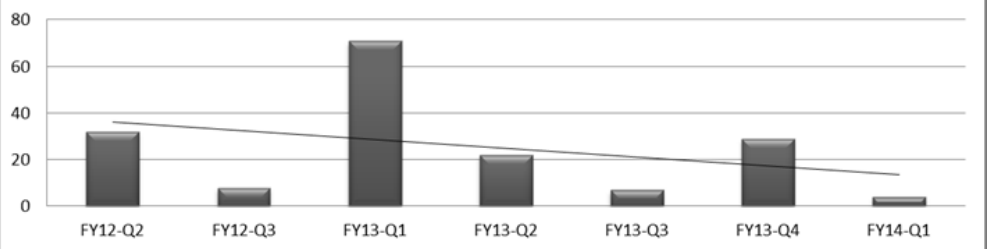




\section{INL Occurrence Trend Snapshots}

From 10/01/2013 through 12/31/2013, INL reported 14 new events to DOE, in accordance with DOE Order 231.1B. These events are analyzed to determine commonalities related to: Operational Emergencies (Group 1), Personnel Safety and Health (Group 2), Nuclear Safety Basis (Group 3), Facility Status (Group 4), Environmental (Group 5), Contamination and Radiation Control (Group 6), Nuclear Explosive Safety (Group 7), Packaging and Transportation (Group 8), Noncompliance Notifications (Group 9), and Management Concerns (Group 10).

In addition, INL reported 16 events through our local issues tracking software that did not meet or exceed the ORPS reporting thresholds. These events are also discussed and analyzed within this report.

\section{TREND SNAPSHOT}

Occurrences by Facility: Both the Material and Fuels Complex (MFC) and Advanced Test Reactor (ATR) facilities saw a slight decrease in the number of events reported during the $1^{\text {st }} Q$ tr FY-14 as compared to the $4^{\text {th }} Q \operatorname{tr} F Y-13$. Because of the nature of work occurring at the ATR and MFC Facilities, it is not unexpected that they report the most number of events.

ATR reported $64 \%$ and MFC $29 \%$ of the events during this reporting quarter. Analysis of the nature and causes of all the reportable events is covered in other sections of this report.

\section{TREND SNAPSHOT}

\section{Occurrences by Reporting Criteria:}

INL continues to experience the majority of events related to Group 2, Personnel Safety and Health, Group 3, Nuclear Safety Basis, Group 4, Facility Status, and Group 10, Management Concerns. Analysis of all reportable events and any noted trends is covered in other sections of this report.
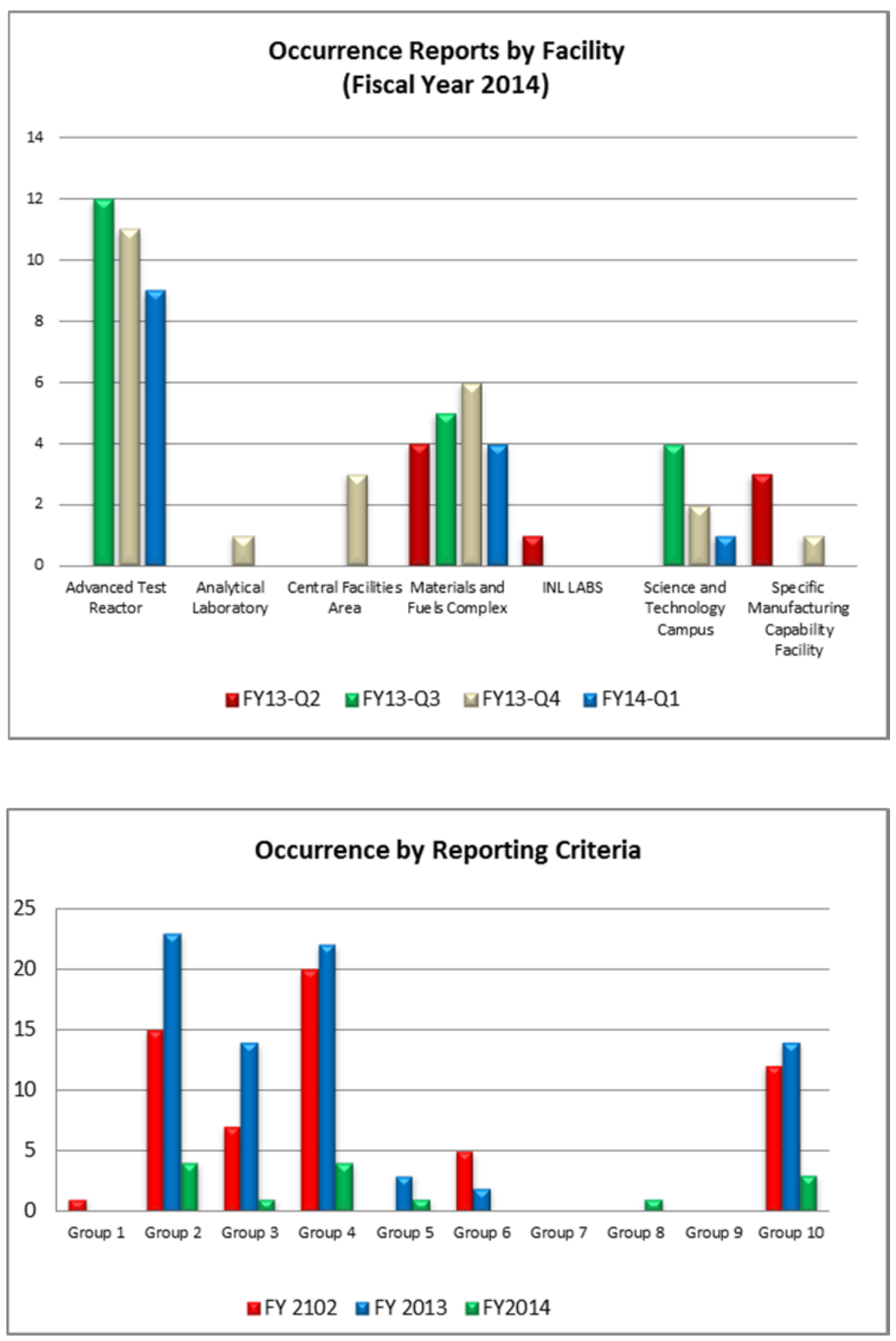


\section{TREND SNAPSHOT}

Lessons Learned Events: For $1^{\text {st }}$ Qtr FY-14 Lessons Learned was not used effectively to maintain a high level of awareness regarding behaviors and managers were not engaged sufficiently to ensure the lessons learned were applied appropriately. Key factors in maintaining likelihood of events are for personnel to exercise high standards with respect to behaviors that can lead to events by relating behaviors to actual events.

The INL Lessons Learned Program is an integral part of the feedback and improvement processes required by DOE. Operational excellence requires the use of internal and external operating experience information (OEI) to prevent recurrence of undesirable conditions and promote noteworthy practices. Lessons learned both positive and negative, are systematically evaluated and implemented to continuously improve performance. During the $1^{\text {st }}$ Qtr FY-14, the INL issued 9 lessons learned, three of which were yellow (Caution) lessons, five of which were blue, and zero red (Urgent) lessons were issued by INL. The yellow lesson and four blue lessons are summarized below.

\section{Power Cable Damaged When Struck by a Transfer Cart Wheel}

(BLUE - 2013-1219)

Recognizing scope creep, combined with proper use of procedures and stop work authority, may prevent an event from occurring. Walking down a job prior to briefing will ensure the entire scope of the job is identified so the required work documents are briefed and the hazards identified and mitigated. If there is any change in scope that was not included in the original job description, a stop work should be exercised. If proper job scope is identified and stop work is exercised when scope creep is realized, new hazards will be properly identified and mitigated in the pre-job briefing and work documents.

On September 25, 2013, operators and riggers were preparing to lift a welding machine out of the Fuel Conditioning Facility (FCF) Suited Entry Repair Area (SERA) bag-in/bag-out area. The welding machine was positioned on the SERA Transfer cart and the pre-job briefing made the assumption that the cart was already positioned under the floor hatches so that the high bay crane could be used to lift the welder two levels up to the main floor. The pre-job briefing covered opening the floor hatches, rigging the welder, lifting the welder out of the basement, and closing the floor hatches.

Once the job began, it was discovered the transfer cart was positioned under the SERA and needed translated out into position under the floor hatches for the lift. Power for cart comes from a wall mounted power cable that must be plugged into the cart prior to moving the cart. The need to ensure the power cable was free of the path of the cart was briefed in the field and an operator positioned the cart under the floor hatches without using the procedure or taking a timeout since the scope of the job had now changed.

The welding machine was then rigged and, after multiple attempts to correct the center of gravity of the load, the welder was hoisted out of the basement. The cart operator observed the rigging operations and then translated the cart back toward the storage position underneath the SERA to make space in the congested room to allow a bottle cart to be lowered to support removal of an argon bottle. The bottle was not hoisted with the welding machine due to center of gravity issues.

Due to the congested area in the SERA bag-in/bag-out area, the 20 foot power cable for the cart must be routed along the side of the cart to prevent the wheels of the cart from running over the cable. The procedure for operating the cart, which was not used during this evolution, contains a warning to the operator to clear the cart path of debris, equipment, and personnel prior to movement. While transferring the cart toward to the storage position, a wheel of the cart contacted and pinched the power cable for the cart which caused the cart to stop. The operator turned off the transfer cart at the 
pendant and made notifications. When making notification to their supervisor, a lack of three way communication caused the operator to think they were directed to disconnect and store the damaged power cable before the damaged cable was electrically isolated.

\section{ANALYSIS:}

At the time of the work evolution, there were many factors that contributed to the event:

The job was planned to have the transfer cart already in position and thus moving the transfer cart, the hazards involved, and the procedure to be used was not part of the pre-job briefing.

The operator did not take a timeout when the scope of the job changed as briefed because the cart needed moved.

Since the use of the transfer cart procedure was not briefed, the operator, who was lacking proficiency running the transfer cart, did not realize the procedure existed, and did not use the procedure for moving the transfer cart. The procedure contains a warning to the operator to clear the cart path of debris, equipment, and personnel prior to movement.

The lack of space in the room when the transfer cart is positioned under the floor hatches leads to an error-likely situation where the power cable is forced to be routed alongside the cart in the vicinity of the wheels.

Once the power cable was struck, the job should have been stopped, the power cable should not have been moved until the damage had been evaluated and any hazards mitigated.

Lack of three way communication led to the misunderstanding that the operator was to unplug and store the cable.

\section{Knowledge Workers - How can I do my job right, every time?}

(BLUE - 2013-1220)

Organizations using knowledge-based workers are at risk for increased error rates during periods of high personnel turnover due to retirements, staff reductions, etc. The use of Human Performance tools for knowledge workers is critical for error prevention in the conduct of expert-based processes. "Errors by knowledge workers, especially engineers, potentially have the greatest adverse impact on safety and economic performance" - INPO 05-002.

\section{Precisely Controlling Evolutions Requires the Thoughtful Use of Procedures and Human Performance Tools}

(BLUE - 2013-1221)

Industry operating experience has shown two extremes regarding the use of procedures and human performance tools. At one extreme, operators followed procedures exactly as written but did not understand the evolution or did not give the task sufficient attention and focus. In these cases, if the plant does not respond properly because of equipment problems or if the procedure is deficient, an event occurs. At the other extreme, many events have occurred in which operators did not follow procedures as written, implemented evolutions with no procedure guidance, or did not properly use human performance techniques that support effective procedure use. Precisely controlling the plant requires the thoughtful use of procedures and human performance tools.

Guidance incorporating industry operating fundamentals for precisely controlling plant evolutions is found in Section 5 of MCP-9502, “ATR Programs Operations Implementation."

On August 24, 2013, at 0823 hours, a slow setback power reduction occurred at the ATR from an indication of high power from \#1 quad thermal power. The reactor was at full power when the M-1 Secondary Coolant System (SCS) pump was started to complete pump run-in checks following maintenance, per OMM-7.4.13.1.2, "Secondary Coolant System Operation." When the M-1 pump was started, the primary inlet temperature dropped 2 degrees causing a higher indicated quad power. There was no indication of reactor power change on the wide range or neutron level recorders. The slow setback cleared after 30 seconds with the reactor at $80 \%$ full power.

ANALYSIS:

The ATR operations organization should have understood the potential risks of starting a secondary pump with the reactor operating. Because we had been successful many times before, the procedure did not provide any guidance to evaluate the quad water power set points for that cycle and determine if a pump startup could be performed. Operations procedures did not include guidance to evaluate the quad water power set points and a less-than-adequate review was performed based on assumptions that the process would not change. Operators assumed there would be no consequences from starting a secondary pump due to past successes. 


\section{Expert Based Processes - Where Things Go Wrong}

(BLUE - 2013-1222)

The successful execution of expert-based processes depends on the accumulated expertise of the workforce. When expertise is lost, gaps in expert-based processes occur and the rate and consequence of errors increase. Changing demographics due to retirement, layoffs, promotions, job rotations, etc. are resulting in a less experienced workforce. Less experienced workers require a greater emphasis on the utilization of HU tools AND improved capture and transfer of knowledge within the organization.

Three separate experiment loading discrepancies were identified, between February 7 and February 25, 2013, during the 153-A outage of the ATR located at INL. While each event had a point in the process where an administrative error was committed that led to the event, the team looked at these errors as symptoms of a more significant issue. The team identified two root causes and three contributing causes.

Under average pressure the Experiment Engineering group could compensate for a lack of a robust process with expert knowledge. The lack of robust processes allowed the engineers to interpret the procedures, and combined with a lack of core human performance behavior knowledge and fundamentals, experiment engineers made imprudent decisions in an attempt to complete the work timely.

\section{ANALYSIS:}

Root Cause 1. The experiment engineering organization lacks core performance behavior knowledge and fundamentals.

Root Cause 2. The experiment engineering procedures are predominantly expert based and do not provide robust direction to adequately capture the rigor needed for critical elements of the experiment loading process.

\section{Technician Receives 120v Electric Shock From Unexpected Source}

(YELLOW - 2013-1223)

Workers must pay special attention for potentially unrecognized hazards when working in areas that have not been accessed for an extended period of time, or when the scope of a routine work activity has changed. A serious accident could result because hazard analysis may not be available or up to date. Failure to respect the potential for an unrecognized hazard resulted in a $120 \mathrm{v}$ shock.

A health physics technician's arm contacted an exposed energized electrical circuit while standing on a ladder and attempting to return a portable radiological meter probe back to its holding place above a valve stationed above a hood that sits atop a radiological glovebox. The technician received a 120 v shock. He was evaluated by medical personnel and released without restriction.

The exposed circuit was one of three exposed terminals on the valve position switch. The circuits and switch had been in use, off and on, for at least 25 years without any known alteration. This same activity had been performed seven times without incident since the system was restarted in November 2012.

\section{Power Lineman Injured While Accessing Bucket Truck (YELLOW - 2013-1225)}

A Power Management lineman slipped while accessing the bucket of lift truck on July 2013. The lineman fell approximately 4.5 feet landing on the deck of the truck. The fall resulted in a fracture and lacerations to the lineman's left forearm.

The event occurred as his four-man crew prepared to remove several abandoned utility poles. The crew had successfully removed one pole the previous week and another that same morning. The lineman was wearing the appropriate footwear and had accessed the bucket without incident during these earlier evolutions. While climbing into the bucket, he grasped the side edges of the bucket with both hands and stepped onto the small step on the outside of the bucket. As he was pulling himself up, his foot slipped off the small step. His crewman provided first aid, notified the supervisor and took him to the dispensary.

The bucket truck was acquired from the Integrated Transportation Services (ITS) equipment pool and is not normally maintained as an assigned piece of equipment dedicated to Power Management. This particular equipment had been used by Power Management for approximately four months prior to the event. There was no hazard identified specifically for accessing the bucket in the work order associated with this event. This is a management concern due to this event being similar to another event that occurred in October 2012, where a lineman was injured while accessing the bucket of a lift truck.

\section{Schedule Pressure - Failure To Identify Pressure Sources on LOTO \\ (YELLOW - 2013-1227)}

Workers must slow down and engage all work with a heightened questioning attitude, especially when encountering real or perceived schedule pressures. Pressurized system isolation devices need to be properly controlled. Failure to properly implement a work order 
resulted in an improper pressurizer relief valve

lockout/tagout.

Due to perceived schedule pressure, an ATR Shift Supervisor and ATR Senior Experiment Operator did not follow standard practices that have been outlined by ATR Operations Management for preparation and approval of a LO/TO. Because they deviated from the standard practices, the SS and SEO committed errors that resulted in an isolation device that was not controlled by the LO/TO during replacement of a pressurizer relief valve.

The work order problems coupled with the outage schedule omissions lead to the SS and SEO experiencing self-imposed schedule pressure. The self-imposed schedule pressure resulted in the SS and SEO performing LO/TO preparation and approval activities in a manner that was not in line with ATR Operations standard practices. To keep in line with operations standard practices; employees preparing a LO/TO are expected to mark up a print with indications of the equipment being isolated (equipment circled), flow paths of hazardous energies annotated (lines highlighted), and indications of the isolation points ( $X$ through valves/breakers/etc.) used to isolate hazardous energy sources. The SEO preparing the LO/TO presents the marked up print to the SS for review during approval of the LO/TO.
ANALYSIS:

Personal Accountability

PA.2 Job Ownership: Individuals understand and demonstrate personal responsibility for the behaviors and work practices that support nuclear safety.

Discussion: During preparation of the LO/TO for replacement of the pressurizer relief valve, the SS and SEO did not demonstrate behaviors and work practices that displayed a strong Nuclear Safety Culture. The work document errors and perceived schedule pressure influenced the SS and SEO to accept substandard work practices.

\section{Questioning Attitude}

QA.2 Challenge the Unknown: Individuals stop when faced with uncertain conditions. Risks are evaluated and managed before work proceeds.

Discussion: The personnel involved in this event did not act on multiple signs of uncertainty; the work order was issued with work instructions for replacing two relief valves when only one relief valve actually needed to be replaced, the prerequisites listed in the work order were not correct for changing the SF-137 relief valve given plant configuration, the SS decided to prepare and post the LO/TO "at risk" based on the changes he expected to be made in the work order on dayshift in order to meet the outage schedule.

\section{$1^{\text {st }}$ Qtr FY-14 GROUP 1 - OPERATIONAL EMERGENCIES}

There were no operational emergencies reported during the $1^{\text {st }}$ quarter of FY-14. The last operational emergency was reported in April 2012, when boron triflouride gas leaked from a neutron detector (NE-ID-BEA-INLLABS-2012-0003). The rate of occurrence of operational emergencies remains zero. 


\section{TREND SNAPSHOT}

Personnel Safety and Health Events: Personnel safety and health events accounted for $29 \%$ of the events reported in ORPS during the $1^{\text {st }} \mathrm{Q}$ tr FY-14. The rate of personnel safety and health issues is trending downwards. Causes of the $1^{\text {st }} \mathrm{Qtr} F \mathrm{FY}-14$ occupational safety events varied and can be primarily attributed to employees, particularly human performance and review of work less-than-adequate.

While there have been a number of LOTO errors during the past 12 months, they are not indicative of a failure of the INL LOTO Program, nor are they due to a failure to implement the LOTO program at the INL site nor at any INL facility. They do indicate ongoing issues with personnel consistently performing work within these controls. INL has ongoing efforts to improve in this area and should see improvement, in time, with consistent effort by management, to monitor work activities and enforce expectations.

There were no similarities in the four personnel safety and health events that occurred this quarter nor in their causes, organizations, or work groups, that would indicate an adverse trend or recurring problem within the last 12 months.

Personnel safety and health occurrences were the second most frequently reported event type, accounting for 19 reportable events in the last 12 months. Four events were reported during the $1^{\text {st }} \mathrm{Qtr} \mathrm{FY}-14$ and are summarized below. Additionally, seven non-reportable events were also reported through the INL issues management software.

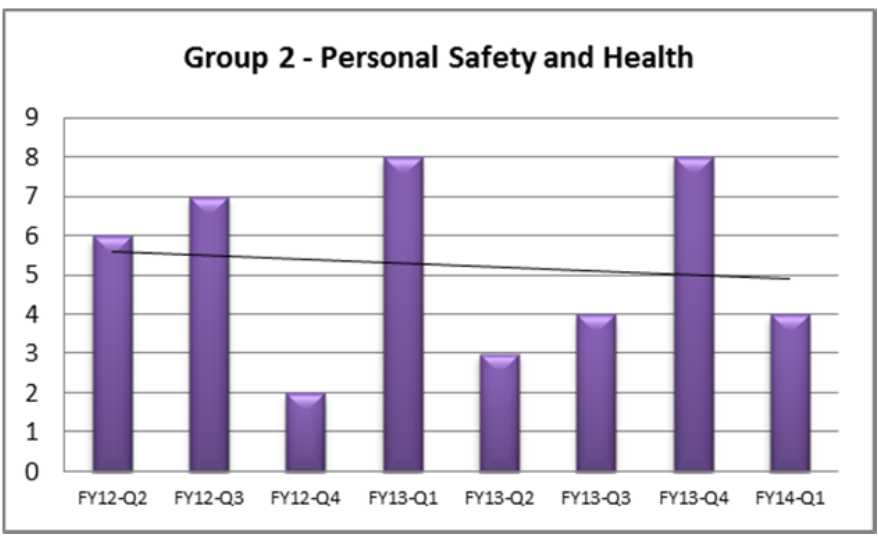

\section{Failure to Document a Zero Energy Source on the LOTO Form}

NE-ID--BEA-MFC-2013-0006 (Significance Category 4) At approximately 1330 hours on November 25, 2013, while reviewing the lockout/tagout (LOTO) paperwork for the removal of an air compressor from MFC-782, it was observed that the paperwork did not have a hazardous energy check for pressure. When the LOTO was installed, the gauge on the old air compressor indicated zero pressure and was verified by checking the pressure relief valve, but was not indicated on the LOTO form. After the LOTO was put into place, a temporary air compressor was connected to the system to supply air to the facility. This temporary connection could allow for air to back feed into the old compressor except for the LOTO' $d$ valve located between the old compressor and the place where the temporary air compressor was connected. This valve was on the LOTO and had been locked and tagged closed to prevent someone from opening the valve once the temporary air compressor was put into service.

The temporary air compressor was immediately turned off and the hose was disconnected from the system. The Building Manager was then notified. The section of pipe that contained the valve was removed at a union and a plug was installed.

\section{Employee Fractures Bone in Wrist Due to Slip and Fall on Ice}

NE-ID--BEA-STC-2013-0005 (Significance Category 3)

On November 21, 2013 at approximately 0630 hours an INL employee slipped and fell in the Willow Creek Building west parking lot on a patch of ice. He fell and impacted his left arm/hand that resulted in some pain in his hand and wrist.

The employee reported the fall to his manager at approximately 1000 hours and was sent to the WCB dispensary for evaluation. 
Facility Management evaluated the WCB parking lot to assess potential slip areas. Facility Management provided direction to subcontractor to add additional salt barrels to several areas in the NW parking lot and focus particular attention on the low-lying areas when applying ice melt.

Even though the patch of ice was in an area that was a little darker due to time of day, a lighting survey of the NW parking area was completed and the lighting was determined to be adequate with no issues identified.

The event occurred at 0630 hours but was not reported immediately to management. Management discovered the event and injury later in the day and they required the employee to seek medical attention. Once discovered, required notifications were completed.

\section{Breaker Isolation Device was Inadvertently Dislodged} NE-ID--BEA-HFEF-2013-0004 (Significance Category 3) During repair of the pneumatic transfer system in HFEF, it was discovered that the LOTO isolation device and two simple locks and tags (installed 10/29/13) had dislodged from the breaker that was being used to secure the power to the system. It appears that the positioning of a master manipulator, at the end of shift or evening of the previous day, inadvertently contacted the LOTO isolation device causing it to release from the breaker. The isolation device was pinned between the wall and the manipulator and could not be readily identified that it was out of its desired condition.

\section{Inadequate Lockout/Tagout (LO/TO) in 2B-SE Primary Cubicle at the ATR}

NE-ID--BEA-ATR-2013-0036 (Significance Category 4)

On October 21, 2013, at approximately 0400 hours, Operations added a work control document line item to LO/TO ATR-LOCS-2437 on experiment loop 2B-SE for Work Order (WO) 111980, Loop In-pile Tube (IPT) Relief Valve 4-year Replacement. At approximately 1400 hours on October 22, 2013, Crafts personnel signed into the ATR-LOCS-2437 LO/TO and entered the 2B-SE primary cubicle for a job walk-down in preparation to start the replacement of the 2B-SE IPT relief valves. Upon completion of the walk-down, Craft personnel exited the 2B-SE primary cubicle. Work was scheduled to start October 23. At approximately 0830 hours, on October 23, the ATR DOE Facility Representative (FR) was reviewing the active LOTO record sheets. During FR review of ATR-LOCS-2437 LOTO, assisted by the ATR Shift Supervisor (SS), the SS discovered that the 2B-SE pressurizer heaters were not part of that LOTO, but are required for work in the $2 \mathrm{~B}-\mathrm{SE}$ cubicle. It is noted that the pressurizer heaters are LOTO de-energized for cubicle entry in LOTO ATR-LOCS-2428. No electrical hazard was present during job walk-down.

\section{Other Non Reportable Events}

There were seven personnel safety and health concerns reported in ICAMS/LabWay in the $1^{\text {st }}$ Qtr FY-14 that did not meet ORPS reporting thresholds. These concerns are as follows:

\section{CO-2013-0410}

On October 17, 2013 an EPRO at the ATR Complex (GB12) developed pain in his left elbow while using long-handled reach tools to perform reactor top work over a multiple hour period. He sought evaluation at the CFA Clinic where a physician assistant determined he developed inflammation in the elbow, provided over-the-counter medication and heat/cold therapy, and released the employee to return to work with restriction, which his management determined did not impact his ability to perform any of his routine job duties. The case was classified as first aid at that time. The employee has been monitored by INL Medical ever since, with some initial improvement noted, but no improvement since. As a result, when the employee returned to the CFA Clinic on December 16, a physician assistant prescribed anti-inflammatory medication and instructed him to increase the frequency of cold therapy. The prescription medication meets the criteria for reclassification of the case from first aid to recordable. The employee continues to be monitored by INL Medical.

\section{CO-2013-0850}

On November 12, 2013 a labor relations staff employee (K600) sought evaluation at the CFA Clinic for pain in her right elbow and forearm, which she related to prolonged use of a computer tablet device over a multi-week negotiation period. A physician assistant evaluated her and determined her symptoms were consistent with a cumulative trauma condition (CTD) present in her elbow. She was instructed to use an orthopedic device not designed to immobilize, apply ice, given over-the-counter (ОTC) medication, and released with instructions to take breaks and obtain an ergonomic evaluation of her workstation. The case was classified as first aid at that time. The employee has been monitored by INL Medical since. When she returned for a follow-up evaluation on November $26^{\text {th }}$ she reported that she had sought treatment offsite for the arm by an acupuncturist, which she reported had some benefit. A physician instructed her to continue with the ice, OTC medication, orthopedic device, and released her to continue work. Treatment by an 
acupuncturist meets the criteria for reclassification of the case to recordable. The employee continues to be monitored by INL Medical.

\section{CO-2013-0686}

On November 26, 2013 a waste tech operator at the ATR Complex (GB12) was passing through the canal area while cask work was being performed when he inadvertently struck his head against a cask hook assembly lift fixture that had pivoted away from the wall. Afterward, the employee noticed he was bleeding, so he made notifications and sought evaluation at the CFA Clinic. A physician cleansed the approximately $3 \mathrm{~cm}$ laceration, closed it using 5 sutures, applied a dressing, and released him to return to work with restrictions, which his management determined did not impact his ability to perform any of his routine job duties. The use of sutures meets the criteria for classification of the case as OSHA recordable.

\section{CO-2013-0736}

On December 03, 2013 at approximately 1000 hours, an Equipment Operator (EO) was using a forklift to unload a pallet-jack from the back of a cargo truck at the INL Research Center (IRC). As the forklift was crossing the threshold into the IRC high bay, it bounced causing the pallet-jack to tip off the forks. The pallet-jack fell approximately 3 feet to the ground damaging the handle of the pallet-jack. No one was near the forklift or injured and work was immediately stopped.

\section{CO-2013-0810}

On Friday, December 6, 2013, after exiting bus 447 at NRF, an NRF employee reported to the driver that they smelled exhaust fumes in the passenger compartment. Later in the morning, three of the sixteen passengers reported smelling exhaust fumes on bus 447 to NRF management. The three passengers were sent to the CFA dispensary and then transported to EIRMC for testing for potential CO exposure.

\section{CO-2013-0519}

On Wednesday, 11/06/2013 at approximately 1850 hours, INL Bus 507 (MFC - Yellowstone Lot) struck and killed a deer on US 20 near mile marker 287. No personnel injuries occurred and damage was limited to front fender and a cracked headlamp cover.

\section{0-030052}

During roof repair work at FCF, individuals in the mockup and high bay areas within FCF noticed the presence of vapors consistent with the construction adhesive used on the roof. Based on previous experience, the area was monitored by Industrial Hygienist. The threshold limit value of 48 ppm was not exceeded. Supervision made the decision to discontinue work in these areas. Four personnel in these areas reported having headaches. The personnel were escorted to the dispensary, examined and released without restrictions. A post-Job review will be held to review what went right and wrong, and to determine if any corrective actions are necessary.

\section{$1^{\text {st }}$ Qtr FY-14 GROUP 3 - NUCLEAR SAFETY BASIS EVENTS}

\section{TREND SNAPSHOT}

Nuclear Safety Basis Events: Nuclear safety basis events accounted for $7 \%$ of the events reported in the $1^{\text {st }}$ Qtr FY-14. Nuclear safety basis events dropped from last quarter, the rate of occurrence of nuclear safety basis is trending downwards.

There were no similarities of the one Nuclear Safety basis event that occurred this quarter nor in their causes, organizations, or work groups that would indicate an adverse trend or recurring problems within the last 12 months.

Nuclear safety basis events were the third most frequently reported event type, accounting for 12 reportable events in the past 12 months. One event was reported during the $1^{\text {st }}$ Qtr FY-14 and is summarized below. 


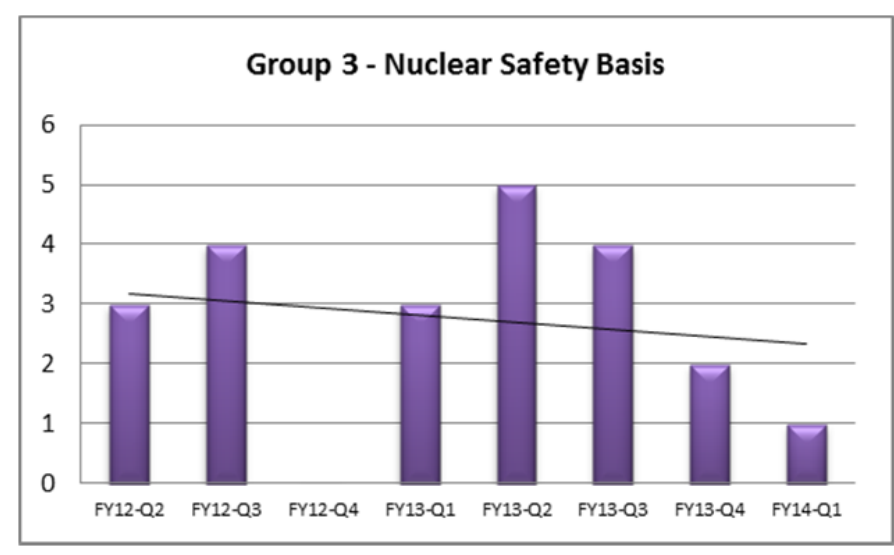

Improper 2E-NW Minimum Void Alarm Setpoint at the Advanced Test Reactor (ATR)

NE-ID--BEA-ATR-2013-0039 (Significance Category 2)

In preparation for reactor startup from Cycle 155A-1 outage, on November 6, 2013 at 0549 hours, 2E-NW minimum void loop alarm setpoints were set and verified by Experiment Operators (EO) according to Core Safety Assurance Package (CSAP), Rev. 0. At approximately 1530 hours, a CSAP revision (Rev. 1), was issued which changed 2E-NW minimum void alarm setpoints. A new alarm setpoint list was delivered to the Loop Control Area (LOCS) and the alarm setpoints were not updated in the control system when the new list was provided. On November 7, while performing pre-startup verification checks, the Senior Experiment Operator (SEO) failed to note that the alarm setpoint displayed on the control system screen did not agree with the CSAP, Rev. 1, alarm setpoint list. All startup preparations were completed and reactor startup was performed on November 7 .

On November 13 at 0137 hours, the reactor was manually shut down due to a problem with the heating and ventilating system that provides confinement conditions during reactor operations. At 0900 hours, an EO noted that $2 \mathrm{E}-\mathrm{NW}$ minimum void alarm setpoint did not match the alarm setpoint list. At
1125 hours, it was confirmed that the wrong alarm setpoint was in place during reactor startup and operation.

The loop minimum void temperature setpoint provides an alarm to the EO that the minimum void temperature is being approached due to an upset in temperature control for the loop. If the upset condition cannot be corrected then the reactor is manually scrammed. Additional alarming loop parameters, independent of the minimum void alarm setting, will exist during a temperature control upset condition to alert personnel of a problem and the need for action including manual reactor scram if the situation cannot be corrected.

ATR Technical Safety Requirements (TSR)-186 surveillance requirement 4.9.1.2 requires that the loop facility operating conditions are within limits specified in the Experiment Safety Analysis Package (ESAP) and CSAP prior to a scheduled startup. This requirement was not met.

\section{Other Non Reportable Events}

There was one additional non-reportable event related to nuclear safety basis problems reported during the $1^{\text {st }} Q$ tr FY-14.

\section{CO-2013-0356}

Cable separation within each of the Emergency Firewater Injection System (EFIS) actuation panels in each of four Plant Protection System Rooms is inadequate. Each panel contains both safety-related and non-safety-related cabling that does not meet separation requirements stated in SAR-153. Each of these panels also contains multiple signal and actuation channels for either vessel level or pressure.

This condition was identified during efforts to resolve similar PPS cable separation issues.

\section{TREND SNAPSHOT}

Facility Status Events: Facility status events accounted for $29 \%$ of the events reported in the $1^{\text {st }}$ Qtr FY-14. The rate of occurrence of facility status events is trending down over the past two years.

There were no similarities of the four Facility Status events that occurred this quarter nor in their causes, organizations, or work groups that would indicate an adverse trend or recurring problems within the last 12 months. 
Events related to facility status have been the most frequently reported event type, accounting for 22 reportable events in the past 12 months. Four facility status events were reported during the $1^{\text {st }}$ Qtr FY-14 and are summarized below.

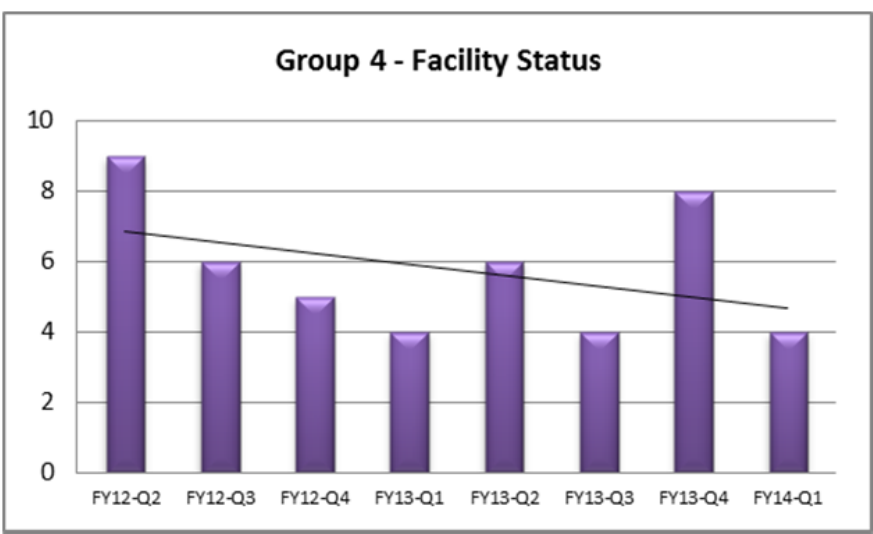

Inadvertent Entry Into Technical Safety Requirement (TSR)-186, Limiting Conditions for Operation (LCO)-3.8.1, Condition B

NE-ID--BEA-ATR-2013-0038 (Significance Category 3)

At 1447 hours on November 11, 2013, Heating and Ventilating System (HVS)-1 failed. On November 12, during a pre-job brief to reset HVS-1, the manually actuated backup damper button was unintentionally engaged causing a Radiation Monitoring System (RMS)-1 trip. Prior to the trip, the main heating and ventilating exhaust (HVE) fan 17B was on-line; however, at 1141 hours, upon recovery from the RMS-1 trip, the HVE 17A fan was started. At 1554 hours, the ATR Operations Assistant Manager discovered two personnel doors into the ATR gas tight area would not close with their closure mechanisms due to a pressure imbalance. The ATR entered TSR-186, LCO-3.8.1, Action B.1 to provide a positive means for doors to shut and seal, or verify a reactor scram within 24 hours.

Efforts to restart HVS-1 failed; therefore, the reactor was shut down at 0137 hours on November 13, 2013, and TSR-186, LCO-3.8.1, was exited at 0209 hours as the action statement no longer applied.

\section{High Inlet Pressure Pump Shutoff Trip During} Pre-Startup Checks at the Advanced Test Reactor (ATR) NE-ID--BEA-ATR-2013-0040 (Significance Category 2) On November 17, 2013 a pressure transient on the primary coolant system (PCS) caused by a standby feature check of the Advanced Test Reactor (ATR) pressurizing pumps resulted in a trip of the High Inlet Pressure Pump Shutoff system. The pump shutoff system protects the PCS from experiencing excessive pressure by automatically shutting off both the pressurizing pumps and the gland seal water pumps.
Following the trip of these two pumps, primary system pressure lowered to a point where the PCS pumps tripped on low pressure. The standby feature check of the pressurizing pump is a routine check performed during reactor pre-start checks which were in progress. System response to this check has routinely come within 1 to 2 psig of causing the trip response to take place.

ATR Technical Safety Requirements (TSR)-186 Limiting Condition for Operation (LCO) 3.2.3.2, Pressurizing and Gland Seal Pump Shutoff System was required to be operable and functioned as designed when a high pressure was reached during the pressure transient initiated by checking the pressurizing pump standby feature. The resulting trip of the PCS pumps also functioned as designed.

\section{Failure of Flow Transmitter (FT)-1-25 at the Advanced Test Reactor (ATR)}

NE-ID--BEA-ATR-2013-0042 (Significance Category 3)

On December 12, 2013, ATR reactor control room personnel noticed transmitter FT-1-25, Primary Coolant System (PCS) to degas tank flow (also known as PCV-1-1 flow), indication was drifting low. The transmitter failed at the low value of -39 gallons per minute (GPM). The range of this instrument is 0-500 gpm, with a normal indication of approximately 220 gpm. Flow transmitter FT-1-25 is one of the required instruments for calculating PCS leak rate. All other required leak rate calculation instruments (pressurizing flow, gland seal water flow, N-16 flow and LCV-1-3C flow transmitters) indicated normal steady values. PCS pressure remained steady at the normal value, as did the degas tank level.

At 2105 hours, the transmitter indication returned to positive values, averaging approximately $175 \mathrm{gpm}$, but fluctuating from 70-240 gpm.

FT-1-25 was declared inoperable and Technical Safety Requirements (TSR)-186, Limiting Conditions for Operation (LCO)-3.3.6, Condition G, was entered. Current and normal methods for determining PCS leak rate are by utilizing gland seal water flow, N-16 flow and LCV-1-3C flow transmitters. FT-1-25 indication is only used in the leak rate calculation when LCV-1-3C flow becomes zero as part of the PCS response to a leak. PCS leakage would need to rise to greater than 13 gpm before LCO actions for FT-1-25 being inoperable would come into play. However, ATR management made the conservative decision to stay in the LCO until the mode of applicability is exited or the indication is fixed. 


\section{Reactor Scram Due to Equipment Failure}

NE-ID--BEA-NRAD-2014-0001 (Significance Category 3) On December 17, 2013 a reactor startup was conducted to perform radiography. After approximately three hours of operation in the automatic mode an automatic reactor scram occurred. The scram was caused by a failure in the automatic control circuit which caused the regulating rod to move out resulting in an automatic high power scram. The scram occurred at $90 \%$ of the power limit.

\section{Other Non Reportable Events}

There were seven facility status events reported in ICAMS/Labway in $1^{\text {st }}$ Qtr FY-14 but did not meet ORPS reporting thresholds. These are summarized below.

\section{IO-029764}

At approximately 1427 hours on October 3, 2013, the NRAD Reactor Operator commenced a normal reactor shutdown. After moving slightly in the inward direction, the regulating rod drive stopped. The Reactor Operator immediately entered NRAD-ONRI-5 Improper Control Rod operation and scrammed the reactor.

\section{IO-029893}

At approximately 1100 hours on October 4, 2013, the HFEF operators were performing routine radiation readings on material samples. It was discovered that several of the sample containers did not contain the sample material. The sampling evolution started in April, 2013 and was suspended for two months due to equipment failure and repair. When the evolution was restarted, operations personnel had not adequately recorded the conditions when the evolution was suspended and assumed the sampling and container loading that had been in progress was completed. The data base was updated to reflect the samples being in the containers, however, the physical transfer had never taken place. The material is still within the bounds of the Material Balance Area and the conservative estimates for material sampling ensured there were no criticality concerns with the transfers.

\section{IO-030050}

On December 12, 2013 an out-of-commerce waste shipment from MFC to AMWTP was performed that included INL Security maintaining a 1,000 meter (600 meter TSR requirement) security perimeter around the shipment. This perimeter is for the stated purpose of protection of the public. At the AMWTP parking lot, a private vehicle entered the lot from a desert road (not intended for Public Access) and came within 600 meters of the shipment.
IO-030257

On November 13, 2013 at 1458 hours; Completed Reactor Startup per NRAD-OI-5100. The Reactor Operator placed the reactor in Automatic Control. At approximately 1534 hours the Reactor Operator received the POWER LEVEL 1 High alarm. The Power Level indications for safety channels 1 and 2, the Linear Channel, and Log Channel were all $83 \%$ and stable. There were no other indications of a power perturbation. The Reactor Operator manually scrammed the reactor in accordance with off-normal response procedures.

\section{CO-2013-0402}

At 1036 hours on October 23, 2013, an email was sent to all ATR Complex personnel that the ATR evacuation sirens would be out of service until further notice. In the event of an evacuation, personnel were to follow directions provided by the physical security force. At approximately 1100 hours, Operations made the same announcement over the ATR Complex paging system. ATR evacuation sirens inadvertently activated during planned maintenance.

\section{CO-2013-0499}

On October 31, 2013 activities were underway to establish a steam bubble in the experiment loop 2D-SW in preparations for reactor start-up. At approximately 1712 hours, during an entry to the loop 2D-SW secondary cubicle, it was noted that there was steam/water in the loop 2D-SW sample glove box and transmitter cabinet. The procedure used to draw a steam bubble in a loop pressurizer (PZR) is written for the pressurizer to be isolated, but does not stipulate this as a prerequisite. In this case, the Senior Experiment Operator (SEO) met the procedure prerequisites, started PZR heaters and unisolated the PZR at 70 psig. Loop pressure was at 95 psig due to makeup head and this delta pressure caused water to flow from the loop to the PZR causing PZR level to increase. Normally the PZR is heated up until pressure in the $P Z R$ is approximately 500 psig. The loop is then pressurized to within 25 psig of the PZR pressure using the loop makeup pumps, and then the PZR is valved into the loop. While not contrary to procedural requirements, the SEO did not recognize that the delta pressure between the pressurizer and loop would cause an increase in pressurizer level. The operators mis-diagnosed the rising PZR level and attributed the rise to the heat up of the water in the PZR and validated this through the use of steam tables. To control pressurizer level the SEO opened the PZR drain valves in accordance with the loop heat up procedure but did not validate that required prerequisites were met including sample box and transmitter cabinet drain valves that connected to a common drain header were shut thus allowing PZR water to flow into the drain header and back up into the sample box and transmitter cabinets. This water flashed to steam and about 1-2 gallons condensed and drained to the cubicle floor. The area beneath the sample glove box is a designated contamination area. The area wet by the condensing steam 
outside of the contamination area was surveyed and one smear was found to read 1560 disintegrations per minute $(\mathrm{dpm}) / 100 \mathrm{~cm}^{2}$ beta gamma, less than $20 \mathrm{dpm} / 100 \mathrm{~cm}^{2}$. This area was decontaminated shortly after the steam was discovered and isolated. All other smears outside of the designated contamination area were less than $1000 \mathrm{dpm} / 100 \mathrm{~cm}^{2}$.

\section{CO-2013-0569}

At 1447 hours on November 11, 2013, the Heating and Ventilating System (HVS)-1 main supply fan variable frequency drive (VFD) failed. At 1123 hours on November 12, 2013, in the reactor control room, the ATR Assistant Manager was briefing on powering down HVS-1 VFD controller to see if it would reset. During the brief, the Shift Supervisor (SS) was explaining that powering down HVS-1 could cause a building Radiation Monitoring System (RMS)-1 trip, which would secure all gas tight building dampers and all H\&V fans. The operating crew would then enter Abnormal Operating Procedure (AOP)-20.2 to restore the plant from the RMS-1 trip. He was showing his operators which buttons needed to be reset, per AOP-20.2, when he pointed to the manually actuated backup damper button and unintentionally engaged the button with his finger, tripping all gas tight backup dampers, which interlocked, causing an RMS-1 trip.

ANALYIS:

Supervisor must maintain a distance from plant equipment to avoid accidental tripping of switches and buttons.

\section{$1^{\text {st }}$ Qtr FY-14 GROUP 5 - ENVIRONMENTAL EVENTS}

\section{TREND SNAPSHOT}

Environmental Events: Environmental events accounted for $7 \%$ of the events reported in the $1^{\text {st }}$ Qtr FY-14. The rate of occurrence of facility status events trended upwards due to 40 CFR, Part 63, Subpart ZZZZ new requirements.

Events related to environmental problems are one of the least reported event type, only accounting for four events in the past 12 months - one of which was reported in the $1^{\text {st }} \mathrm{Qtr}$ FY-14. This event is described below.

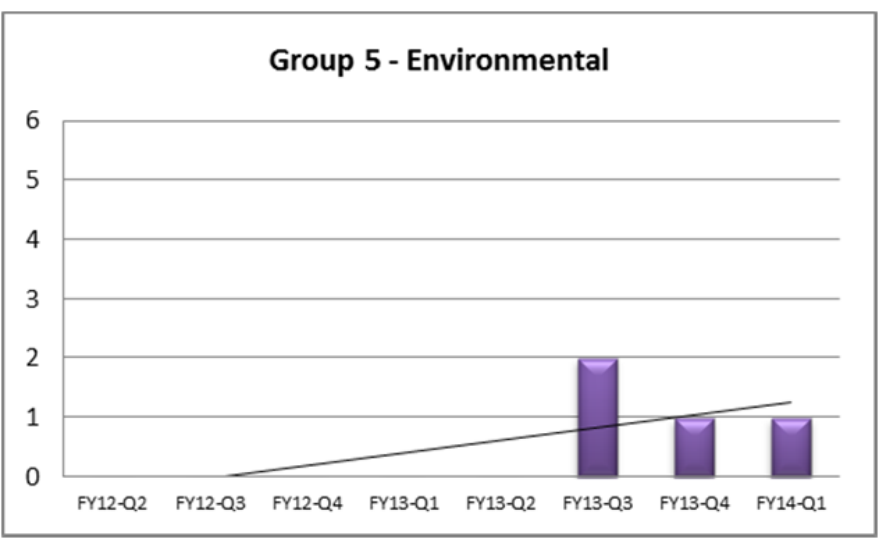

\section{Quarterly Report of Diesel Engine Startup at the Advanced Test Reactor (ATR)}

NE-ID--BEA-ATR-2013-0034 (Significance Category 4)

The following new environmental regulations operation and maintenance requirements for ATR Complex diesel engines are in effect: 40 CFR, part 63, subpart ZZZZ, National
Emissions Standards for Hazardous Air Pollutants for stationary Reciprocating Internal Combustion Engines (RICE), also known as Quad Z.

The following ATR Complex engines are non-emergency stationary RICE: generators 670-M-42, 670-M-43, and 674-M-6.

Without installation of emissions controls, units 670-M-42, 670-M-43, and 674-M-6 did not meet the new emission standards for hazardous air pollutants beginning May 2, 2013. INL has negotiated with the Idaho Department of Environmental Quality (DEQ) a Voluntary Consent Order (VCO) to replace units 670-M-42 and 670-M-43 with a commercial power based uninterruptible power supply (UPS). When the UPS project is complete in 2015 , all three units will be designated as emergency stationary RICE.

Every startup of 670-M-42, 670-M-43, and 674-M-6 diesel generators results in an excess emissions event which are not covered in the VCO and is therefore a non-compliance to Quad Z and is reportable. On May 8, 2013, DOE-HQ agreed that a quarterly report is sufficient for reporting these events. 


\section{Other Non-Reportable Events}

There were no additional non-reportable events due to environmental events.
At the ATR Complex, every startup of 670-M-42, 670-M-43, and 674-M-6 diesel generators results in an excess emissions event which are not covered in the VCO and is, therefore, a noncompliance to Quad Z and is reportable.

\section{$1^{\text {st }}$ Qtr FY-14 GROUP 6 - CONTAMINATION/RADIATION CONTROL EVENTS}

Events related to contamination and/or radiation control are some of the least reported event types at the INL, only accounting for two events in the past 12 months. There were no contamination/radiation control events reported in the $1^{\text {st }}$ Qtr FY-14.

\section{Other Non-Reportable Events}

There was one additional non-reportable event due to contamination or radiation control events and has been described under the facility status events section of this report (CO-2013-0499).

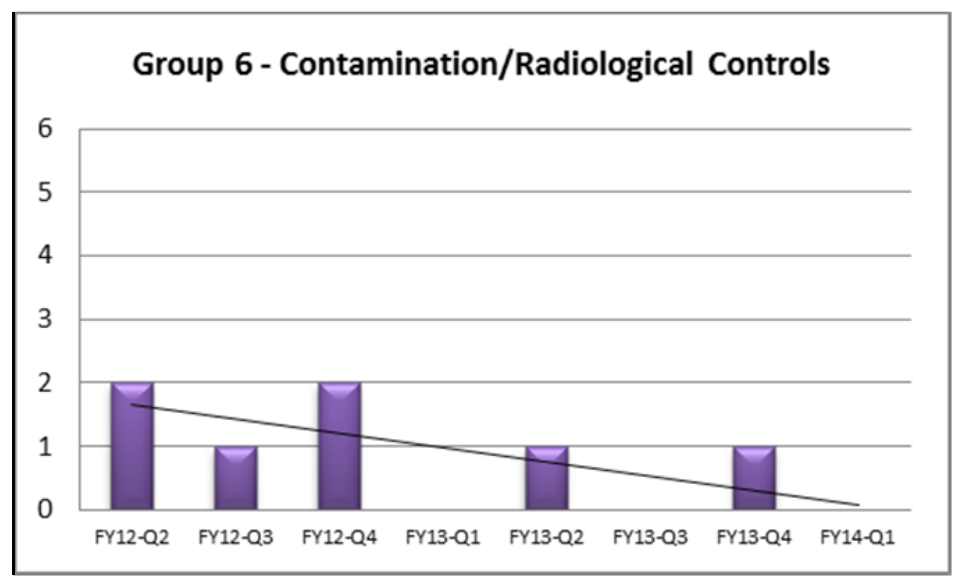

\section{$1^{\text {st }}$ Qtr FY-14 GROUP 7 - NUCLEAR EXPLOSIVE SAFETY EVENTS}

There were no events related to nuclear explosive safety during the $1^{\text {st }}$ quarter FY-14. BEA has never reported an event under this reporting criteria since taking over the contract for the INL in 2005.

\section{$1^{\text {st }}$ Qtr FY-14 GROUP 8 - PACKAGING AND TRANSPORTATION EVENTS}

\section{TREND SNAPSHOT}

Packaging/Transportation Events: Packaging and transportation events accounted for $7 \%$ of the events in the $1^{\text {st }}$ Qtr FY- 14 . This is the first event since $4^{\text {th }}$ Qtr FY-14.

Events related to packaging and transportation rarely occur at INL; there has been one such event in the last two years. In $1^{\text {st }}$ Qtr FY-14 there was one ORPS reportable event. This event is described below. 


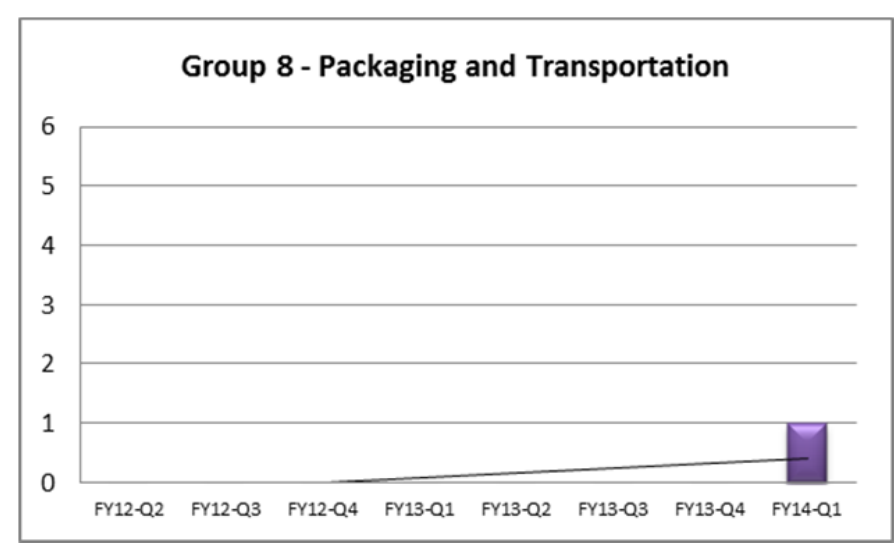

\section{Unsecured Drums in Exclusive Use Trailer Discovered at Destination}

NE-ID-BEA-ATR-2013-0035

On October 3, 2013 a commercial trailer and driver arrived at Y-12 Union Valley receiving facility with an exclusive use shipment from the Idaho National Laboratory containing UN3328, radioactive material, type $B(U)$ package, fissile, 7 , $\mathrm{U}-234$, solid, oxide material. When the doors were opened, the contents were observed unsecured in the trailer. The containers were discovered lying on their sides and scattered about the interior of the trailer. There was broken metal banding on the trailer floor and a web-type ratchet strap that

\section{$1^{\text {st }}$ Otr FY-14 GROUP}

was still secured to the trailer side rails on both ends near the front of the trailer. None of the containers were broken open and there was no visible exterior damage. Written notification was sent by Y-12 to INL Logistics Services on October 7, 2013 at 1000 hours.

\section{BACKGROUND:}

The five drums were strapped to a metal pallet in preparation for shipment on an exclusive use truck and trailer provided by a commercial carrier.

The shipper saw the pallet with the drums taken to the front of the trailer by the driver of the truck and trailer on a pallet jack and set against the front of the interior of the trailer. $A$ ratcheted web strap for securing freight was fastened from one side of the trailer around the palletized drum and secured to the same side of the trailer in the front.

There have been no reports of similar failure of metal straps for INL shipments.
Noncompliance notification events occur when the INL receives written notification from an outside regulatory agency that the site or an INL facility is considered to be in noncompliance with a schedule or requirement. Over the past 12 months, zero noncompliance notification events have been reported through ORPS.
Recurring Occurrence - A series of two or more events determined by performance analysis to have an unacceptable high frequency and severity, for which previous corrective actions failed to prevent repetition within a 12-month period.

EFCOG Contractor Guide for Performance Analysis

\section{$1^{\text {st }}$ Qtr FY-14 GROUP 10 - MANAGEMENT CONCERNS AND ISSUES}

Events reported as management concerns or issues accounted for $21 \%$ of the events reported during the $1^{\text {st }}$ Qtr FY-14 and $18 \%$ of those reported over the past 12 months. Three events were reported during the $1^{\text {st }}$ Qtr FY-14 and are summarized below.

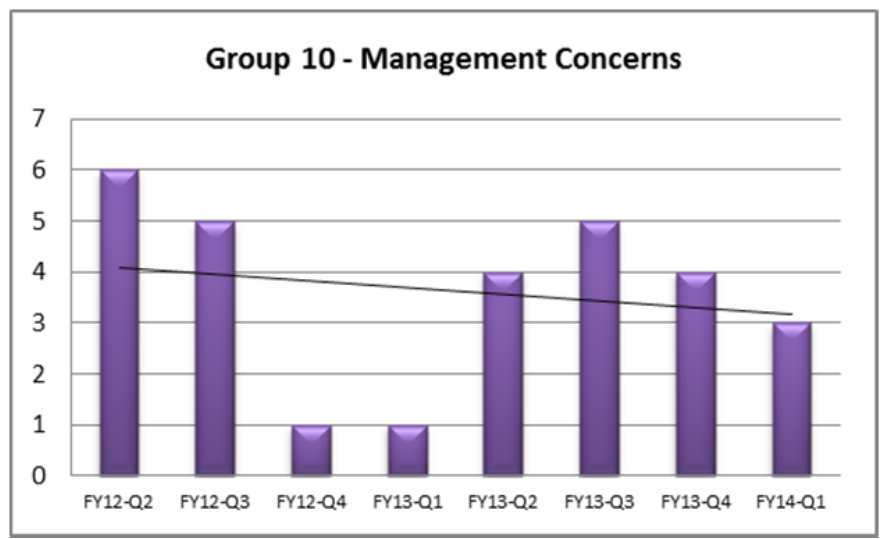


Inadvertent Entry Into TSR LCO Due to Isolating Firewater Path with Irradiated Fuel in Reactor Core NE-ID-BEA-ATR-2013-0037 (Significance Category 3) At 1305 hours on November 4, 2013, an ATR Process Operator discovered that the upper and lower emergency firewater injection systems (EFIS) had been inadvertently isolated during a primary coolant system (PCS) startup evolution. The shift supervisor N/A'd a step in the detailed operating procedure but failed to N/A the sub-step on the next page. The operators starting on the sub-step that should have been N/A'd isolated upper/lower emergency firewater injection system.

The process operator returned to the reactor control room to sign off the master DOP for the steps he had completed on his working copy. In the process, he recognized that the first step completed should have been N/A'd and not performed. He notified the SS who realized they had incorrectly isolated both EFIS upper and lower firewater flow paths and immediately entered Technical Safety Requirements (TSR)-186, Limiting Conditions for Operation (LCO)-3.2.1.2, Condition F, which requires the PCS to be in depressurized shutdown in 4.5 hours.

Probabilistic Risk Assessment (PRA) evaluation was performed with the firewater path isolated for less than 4 hours which provided an insignificant fuel damage risk.

This event was originally categorized at 1344 hours on November 4, 2013 as a TSR and other hazard control violation, significance category 2 . It was re-categorized during the critique held at 1700 on November 4, 2013, therefore; the 2 hour categorization requirement was seemingly missed.

\section{Small Leak Discovered in the ATR M-17 Cation Tank Resin Discharge Line}

NE-ID-BEA-ATR-2013-0041 (Significance Category 4)

At 0515 hours on November 21, 2013, the lead senior reactor area operator (LSRAO) reported to the ATR control room supervisor (CRS) that water was coming from the valve corridor in the bypass demineralizer area by the $\mathrm{M}-17$ demineralizer inlet valve. Further investigation and primary leak rate calculation showed an increase of $5 \mathrm{gpm}$ in the primary coolant system (PCS) leak rate. At the time of identification, ATR was in a reactor outage.

At approximately 0517 hours, ATR Operations entered Abnormal Operating Procedure (AOP)-1.3, "Increased PCS
Leakage." At 0544, RadCon set up a barrier at the bypass demineralizer entrance and set dams to prevent water from spreading inside the ATR building radiological buffer area (RBA); Operations isolated the bypass demineralizer. A work package was written to inspect the M-17 cation tank, which was performed at approximately 2200 hours on November 22, 2013. The initial inspection found that there was approximately 5 feet of water in the bottom of the M-17 cation tank vault, but no indication of where the leak was coming from. At approximately 1320 hours on November 22, the M-17 cation tank was supplied with low-pressure demineralized water (LDW) and inspections of the M-17 tank found the 2 inch diameter resin discharge line had a pencil size through wall leak. The M-17 cation tank was isolated.

The ATR PCS has a radiographic boundary requirement per the SAR-153, Chapter 15. The M-17 cation tank is outside of the radiographic boundary required by the safety basis.

\section{Air Compressor Fell Off Moving Rollers at MFC-782} NE-ID-BEA-MFC-2013-0005 (Significance Category 3) Two subcontracted employees were in the process of replacing an air compressor that supplies air to the Materials and Fuels Complex (MFC) Machine Shop, building MFC-782 when the air compressor tipped over and fell to the ground. The compressor is located in a small outbuilding adjacent to the Machine Shop. The old compressor had been removed from the building and the new air compressor, having been staged inside the building the day before, was being moved into its desired location. The new compressor is a rotary screw compressor weighing approximately 1,500 pounds and was noted as having a high center of gravity.

The subcontracted employees began moving the air compressor using Hilman Rollers and push bars. The compressor was almost into position when it began to tip backwards causing the rollers to become dislodged from underneath the unit; the air compressor fell backwards to the ground. The employees were not in the path of the falling compressor and neither was injured as a result of the event. Damage to the air compressor was minimal. Work was immediately stopped pending an investigation and development of corrective actions by the subcontracted business representatives. No personnel were harmed or injured, and work was immediately stopped. Should someone had been in the way of the piece of equipment as it fell, they certainly could have been injured. The likely injury would have been reportable under LWP-9301. 


\section{TREND SNAPSHOT}

Events Involving Subcontractors: One event has been reported since $1^{\text {st }}$ Qtr FY-14. The trend has been flat at approximately 2 subcontractor events per quarter for the last 2 years.

There have been thirteen events involving subcontractors reported through ORPS during the past two years. One was reported this quarter and has been described under the personnel safety and health section of this report

(NE-ID-BEA-MFC-2013-0005 [Significance Category 3]).

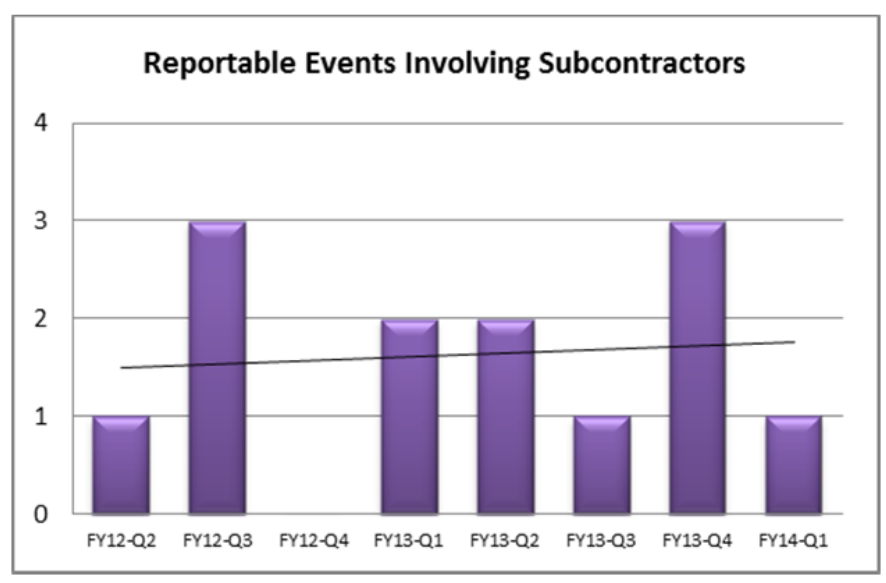

$1^{\text {st }}$ Qtr FY-14 ANALYSIS OF CAUSES OF REPORTABLE EVENTS
Cause analysis results document in ORPS were analyzed to determine trends, within the causes identified, over the past two years and during the past 12 months.

The analysis shows that the majority causes over both time periods can be attributed to management and human performance problems, followed closely by problems with written communications. Specifically, management problems associated with change management and with less-than-adequate (LTA) supervisory methods were most often identified. Human performance problems primarily exist due to knowledge-based errors committed by workers because they justified their actions based upon previously successful work evolutions and because they made incorrect assumptions about the tasks they were performing.

The human performance causes were often coupled with less-than-adequate communications, specifically, less-than-adequate written communications. 


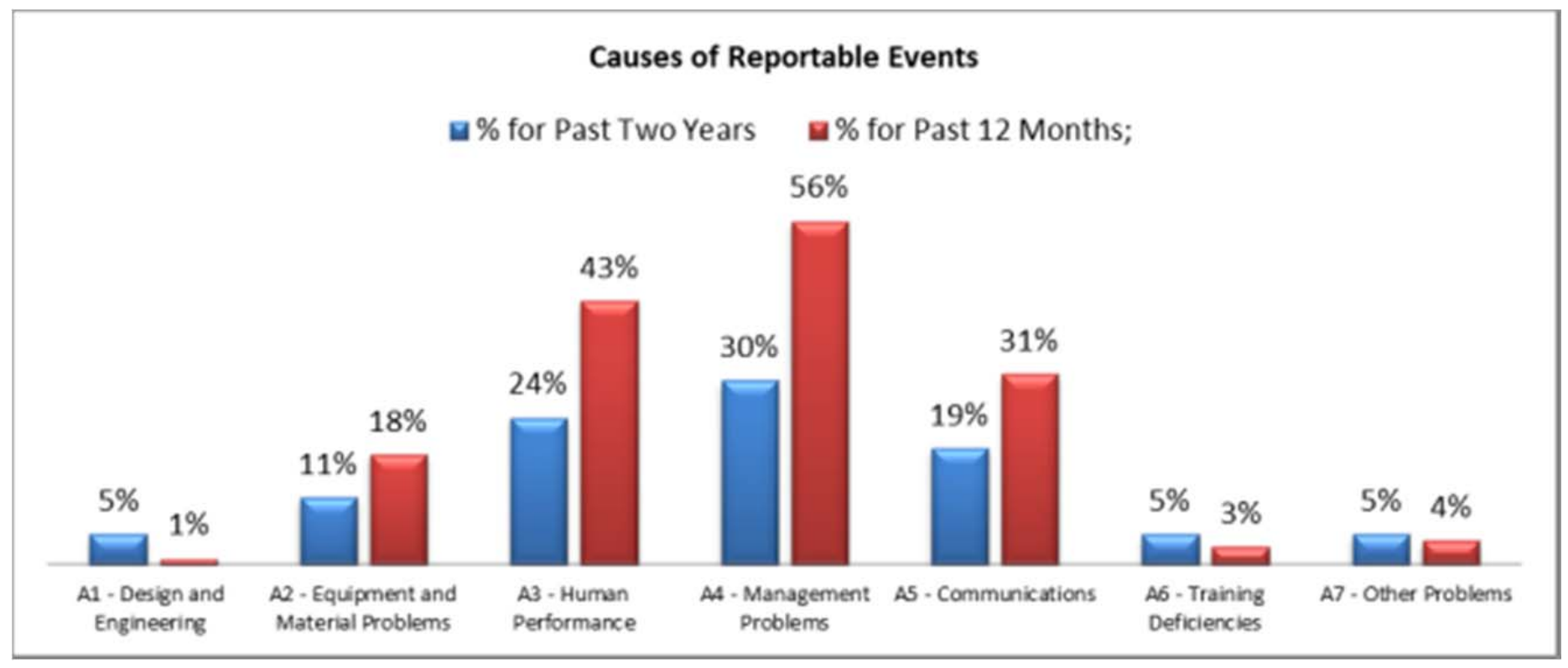

$1^{\text {st }}$ Qtr FY-14 ANALYSIS OF IOPAC TRENDING ANALYSIS

\section{Issues common across the INL:}

- $\quad$ Procedure adequacy, procedure compliance, and less-than-adequate work documents continue to be problems.

\section{Issues that continue to affect various mission centers:}

- $\quad$ Supervisors did not fulfill their expected oversight roles typically by becoming overly engaged in conducting activities or facilitating problem-solving.

- Workers did not fully understand or anticipate the effects of their actions. Weaknesses in worker knowledge and understanding were hard to recognize through standard observations.

- $\quad$ Risk was not recognized or was inappropriately accepted by individuals or the organization without sufficient engagement of others in decision-making. Sometimes because the activities were viewed as routine or because they had been completed successfully in the past.

- Subtle declines in standards and performance went unnoticed because managers and supervisors were not sufficiently engaged in activities. As a result they did not recognize and address repetitive and long-standing personnel performance which resulted in a decline in standards. 


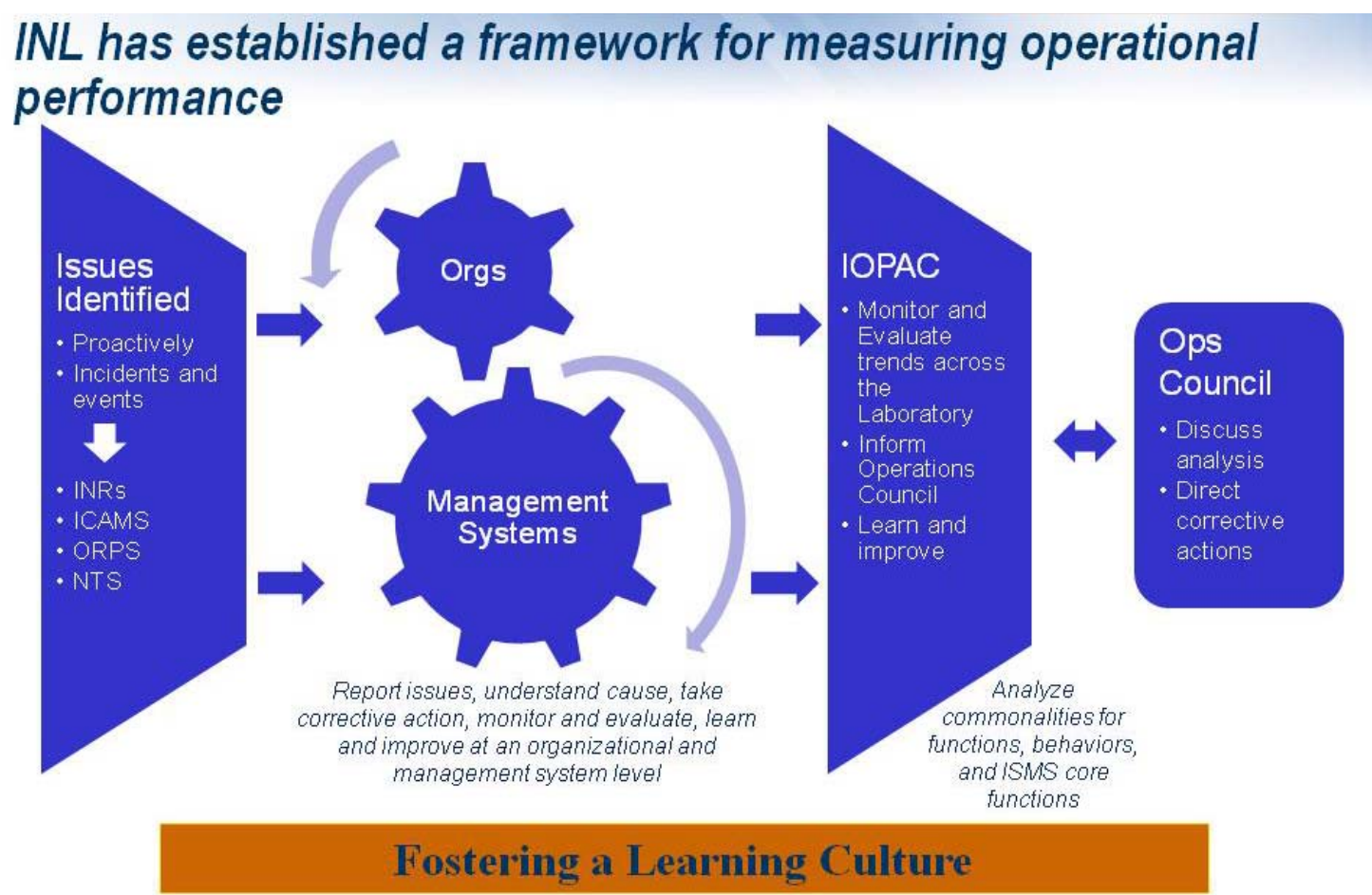

Figure 1. Framework for Measuring Operational Performance. 


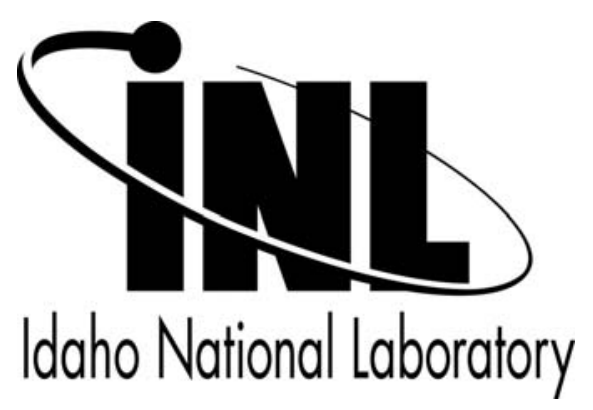




\section{INL Laboratory Performance Expectations}

The INL mission involves performing and deploying world class research that meets the nation's needs in the areas of nuclear energy, other energy, the environment, and national security. Laboratory Performance plays a critical role in supporting the INL mission. Our mission is to:

- Ensure we as a Lab know how we are doing and are improving our performance.

- Own and manage the Laboratory Issues Management System.

- Provide high quality QA program support for research and operations.

- Provide effective independent oversight.

"In order to be successful, we must be leaders, we must be competent, and we must be accountable. We must also exhibit the INL values of excellence, integrity, ownership, and teamwork." - Chris Hott, Director - INL Laboratory Performance

Idaho National Laboratory

INL Laboratory Performance

P. O. Box 1625, Mail Stop 3206

Idaho Falls, ID 83415

INL/EXT-14-31237 